Received December 9, 1968.

' Clark, B. F. C., Doctor, B. P., Holmes, K. C., Klug, A., Marcker, K. A. Morris, S. J., and Paradies, H. H., Nature, 219, 1222 (1968).

${ }^{2}$ Holley, R. W., Apgar, J., Everett, G. A., Madison, J. T., Marquisee, M. Merrill, S. H., Penswick, J. R., and Zamir, A., Science, 147, 1462 (1965).

${ }^{3}$ Doctor, B. P., in Methods in Enzymology (edit. by Crossman, L., and Moldare, K.), 12, Part $A, 648 \mathrm{C}$ (Academic Press, New York, 1967).

4 Fuller, W., Hutchinson, F., Spencer, M., and Wilkins, M. H. F., J. Mol Biol., 27, 507 (1967).

${ }^{5}$ Arnott, S., Hutchinson, F., Spencer, M., Wilkins, M. H. F., Fuller, W., and Langridge, R., Nature,211, 227 (1966).

'Arnott, S., Wilkins, M. H. F., Fuller, W., and Langridge, R., J. Mol. Biol. 27,535 (1967). 'Arnott, S., Wilkins, M. H. F., Fuller, W., Venable, J. H., and Langridge, R.,

${ }^{8}$ Fuller, W., and Hodgson, A., Nature, 215, 817 (1967).

\section{Isolation and Characterization of a Toxin from the Florida Red Tide Organism}

EVIDENCE for a causal relationship between blooms of the Florida red tide organism, Gymnodinium breve Davis, and mass mortalities of marine animals seems well established ${ }^{1}$. In most cases the mortalities can be ascribed to a toxin which has been isolated from a bloom, as well as from laboratory cultures of $G$. breve ${ }^{1,2}$. Other studies have been concerned with physiological and some chemical properties of the toxin ${ }^{2-6}$.

Two toxins were isolated from laboratory cultures and blooms of $G$. breve. An acidified sample of seawater was extracted with chloroform and one toxin (substance I) could be isolated in small amounts from the bubbles at an interfacial layer. A second toxin (substance II) was isolated by passing the clear chloroform extracts over a silica gel column, washing the column with methylene chloride, eluting the residue material with absolute ethanol, and evaporating the ethanol effluent. The residue was dissolved in carbon tetrachloride, stirred with bone charcoal, and the solvent was removed.

The material thus isolated was a pale yellow low-melting solid which was toxic to Fundulus similis. Substance II is a neurotoxin, as indicated by inhibition of acetylcholinesterase activity, and as measured by a standard technique ${ }^{7}$ Quantitative analytical data indicate an empirical formula of approximately $\mathrm{C}_{90} \mathrm{H}_{162} \mathrm{O}_{17} \mathrm{P}$. The absence of nitrogen was indicated by qualitative and quantitative analysis. A molecular weight of 650 (chloroform) was obtained. This value suggests the existence of two fragments in chloroform, though only one fraction was isolated using silica gel (thin-layer or column) chromatography. Substance II (in absolute ethanol) was optically active, $[\alpha]_{589 \mathrm{~m} \mu}^{25^{\circ}},+68^{\circ}$.

On the basis of infrared absorption spectra, samples of substance II whether isolated from cultures or blooms of $G$. breve seem to be identical. Substances I and II are evidently different; the infrared spectrum of the former has a band ascribed to a carbonyl stretching frequency.

The structure of substance II is unknown, but the infrared, nuclear magnetic resonance, ultraviolet and mass spectral data are consistent with the tentative formulation of a major fragment as $\mathrm{OP}\left(\mathrm{OCH}=\mathrm{CH}_{2}\right)$ $\left(\mathrm{OCH}_{2} \mathrm{CH}=\mathrm{CH}_{2}\right)$. Further study of these toxins is in progress.

This work was supported by the US Department of the Interior, Bureau of Commercial Fisheries.

Dean F. Martin Ashim B. Chatterjee*

University of South Florida,

Tampa, Florida.

Received November 11, 1968.

* Permanent address: Jadavpur University, Calcutta.

${ }^{1}$ Rounsefell, G. A., and Nelson, W. R., US Fish Wildlife Serv. Spec. Sci. Kep. Fisheries, No.535 (1966).
${ }^{2}$ MeFarren, E. F., Tanake, F., Silva, F. J., Wilson, W. B., Campbell, J. E., and Lewis, K. H., Toxicon, 3, 111 (1965).

${ }^{3}$ Cummins, J. M., Stevens, A. A., Huntley, B. E., Hill, W. F., and Higgins, J. E., in Drugs from the Sea (edit. by Freudenthal, H. D.) (Marine Technology Soc., Washington, 1968).

4 Starr, T. J., Texas Rep. Biol. and Med., 16, 500 (1958).

5 Sasner, jun., J. J., dissertation, Univ. California, Los Angeles (1965).

${ }^{6}$ Shilo, H., Bact. Rev., 31, 180 (1967).

Jensen Holm, J. H., Lausen, H., Milthers, K., and Moller, K. O., Acta Pharmacol. Toxicol., 15, 384 (1959).

\section{Geographical Variation in Fallow Deer (Dama dama L.)}

IN Great Britain fallow deer are distributed widely and are the most common species in deer parks. It is not known if this deer is indigenous to Britain or whether it was introduced during historic times; popular belief has it that it was introduced by the Romans.

Before fossil or archaeological specimens can be com. pared with contemporary animals it is necessary to know the extent of variation which occurs in recent material. A knowledge of such variation is also interesting from the taxonomic point of view. Even now species are sometimes created, combined or confirmed by taxonomists on evid. ence from very few specimens and with little or no know. ledge of the variation that may occur both within and between populations. This is particularly the case with the larger animals of which it is not easy to obtain large numbers of specimens. Thus when more than 120 fallow deer mandibles became available for study we decided to try to find some measurement or index which was independent of age and which could be used to find whether present populations varied from each other.

Fifty-one specimens of mandibles from wild deer were obtained from Essex, eighteen from Hampshire and eighteen from Dumfriesshire and thirty-six specimens from park deer were obtained from Surrey. The specimens from Essex were obtained from animals killed after they had been involved in accidents and the other specimens were obtained from animals culled in order to control their numbers. The following measurements were made. (1) The length of the mandible from the proximal edge of the alveolus of the canine to the hind margin of ramus ascendens. (2) The height of the mandible from the top of the coronoid process to the lowest point on the angle of the mandible. (3) The length of the cheek teeth (premolars and molars) from the distal end of the alveolus of the second premolar to the proximal end of the alveolus of the last molar erupted or erupting. (4) The length of the diastema from the proximal edge of the alveolus of the canine to the distal edge of the alveolus of the second premolar.

A plot of all these measurements against age revealed that growth of the mandible was rapid during the first $2 \mathrm{yr}$ of life, after which the rate of growth declined considerably and it had almost stopped by about $2.5 \mathrm{yr}$ of age. There is no method known of determining the age of fallow deer older than about $3.5 \mathrm{yr}$ and, although growth of the mandible is almost negligible at this age, the precise rate of change is unknown. It is clear therefore that none of our measurements can be used directly to determine whether there is any difference between populations. Preliminary ealculations showed that the index obtained by expressing the length of the diastema as a percentage of mandibular length was independent of age for each sex and for each of the four populations. The mandibles from the four populations were each divided into two groups for each sex. The first group comprised animals in which the cheek teeth were still erupting, that is, immature specimens, and the second group those animals in which all the cheek teeth had erupted, that is, adult specimens. The indices for both groups were then compared for each population and no significant differences were found, $P>0 \cdot 1$ in every case. 